(2) Open Access Full Text Article

\title{
Update on raloxifene: role in reducing the risk of invasive breast cancer in postmenopausal women
}

\author{
This article was published in the following Dove Press journal: \\ Breast Cancer:Targets and Therapy \\ 19 October 2011 \\ Number of times this article has been viewed
}

\section{Victor G Vogel}

Cancer Institute, Geisinger Health System, Danville, PA, USA
Correspondence: Victor G Vogel Cancer Institute, Geisinger Health System, $100 \mathrm{~N}$ Academy Avenue, Danville, PA 17822, USA

Emailvgvogel@geisinger.edu

\begin{abstract}
Risk factors allow us to define women who are at increased lifetime risk for breast cancer, and the most important factor is age. Benign breast disease increases risk, and the most important histologies are atypical lobular or ductal hyperplasia and lobular carcinoma in situ. Family history of breast cancer among first-degree relatives (mother, sisters, daughters) also increases risk. Quantitative measures of risk give accurate predictions of breast cancer incidence for groups of women but not for individual subjects. Multiple published, randomized controlled trials, which employed selective estrogen receptor (ER) modulators (SERMs), have demonstrated consistent reductions of $35 \%$ or greater in the risk of ER-positive invasive and noninvasive breast cancer in postmenopausal women. Professional organizations in the US now recommend the use of SERMs to reduce the risk of breast cancer in high-risk, postmenopausal women. Raloxifene and tamoxifen reduce the risk of ER-positive invasive breast cancer with equal efficacy, but raloxifene is associated with a lower risk of thromboembolic disease, benign uterine conditions, and cataracts than tamoxifen in postmenopausal women. No evidence exists establishing whether a reduction in breast cancer risk from either agent translates into reduced breast cancer mortality. Overall quality of life is similar with raloxifene or tamoxifen, but the incidence of dyspareunia, weight gain, and musculoskeletal complaints is higher with raloxifene use, whereas vasomotor symptoms, bladder incontinence, gynecologic symptoms, and leg cramps were higher with tamoxifen use.
\end{abstract}

Keywords: selective estrogen receptor modulators (SERMs), raloxifene, risk reduction, chemoprevention

\section{Risk factors for breast cancer}

A number of factors are known to increase a woman's lifetime risk of developing breast cancer, although few of them can be modified. ${ }^{1-4}$ Race, age at menarche and first live birth, nulliparity, the presence of benign breast disease, and a family history of breast cancer all influence the risk of developing invasive breast cancer. We review here the factors contributing most to risk, which are used to select women who are candidates for reducing risk with selective estrogen receptor (ER) modulators (SERMs) such as raloxifene.

\section{Benign breast disease}

Benign breast disease (BBD) includes chronic cystic mastitis, fibroadenoma, fibrocystic disease, and related lesions. The most informative classification schema is based on histopathology. Proliferative disease accounts for between one-fourth and one-third of all biopsies for BBD, and 5\%-10\% of proliferative lesions show cellular atypia, 
which increases the risk of breast cancer five-fold. Several pathologic entities are associated with an enhanced risk of breast cancer. ${ }^{5,6}$ Sclerosing adenosis increases the risk of breast cancer by approximately $20 \%$. There is a slight increase in the risk of breast cancer among women more than 50 years of age with benign lesions that are in the lower category of risk: cyst, adenosis, mammary-duct ectasia, fibrosis, metaplasia, fibroadenoma, mild-to-moderate or florid hyperplasia without atypia, and papilloma.

The relative risk (RR) for breast cancer associated with atypia is approximately four-fold, compared with an RR of 1.8 for proliferative changes without atypia and of 1.27 for nonproliferative lesions. No increased risk is found among women with no family history and nonproliferative findings. In the first 10 years after biopsy, an excess of cancers occurs in the same breast, especially in women with atypia. Therefore, risk factors for breast cancer after the diagnosis of benign breast disease include the histologic classification of a benign breast lesion and a family history of breast cancer.

\section{Family history of breast cancer}

Genetic factors contribute to approximately $5 \%$ of all breast cancers, but to $25 \%$ of cases diagnosed before 30 years of age. ${ }^{7,8}$ Early-onset breast cancer is that which occurs before age 50, at which point there is a flattening in the rate of increase in the age-specific incidence rates. A family history of breast cancer in a first-degree relative (mother, sister, or daughter) has an additive effect with proliferative changes or atypia on the subsequent risk of breast cancer. The effect of family history upon a woman's risk of breast cancer decreases with increasing age; after age 60, age itself is the most important risk factor in the absence of genetically determined familial risk.

\section{Quantitative risk assessment and the Gail model}

A large literature pertaining to the epidemiology of breast cancer has led to the development of validated, quantitative, risk-assessment models..$^{9-11}$ The models allow for the rapid identification of women who are at increased risk for breast cancer, along with an estimation of their probability of developing breast cancer over a period of years or by a certain age. These multivariable risk models allow determination of the short-term risk for breast cancer, and the cumulative lifetime risk, adjusted both for all risk factors taken together and for competing causes of mortality. Risk is then expressed as the percentage chance that a woman will ever develop breast cancer. Published data are derived largely from studies of white women in North America, and the generalizability of these data to other racial and ethnic groups is uncertain. Expressing the risk of developing breast cancer in quantitative terms can help to educate individual patients about their personal risk. It has also led to the rational design of prospective interventional and management strategies that now inform the selection of eligible participants for clinical risk reduction with SERMs.

In 1989, Gail and his colleagues developed a model for estimating the risk of breast cancer in women undergoing annual mammographic screenings. ${ }^{9,10}$ Although the Gail model has been validated for predicting total breast cancer risk in several settings, including both pre- and postmenopausal women, the utility of the Gail model for predicting ER-positive compared with ER-negative breast cancers in postmenopausal women had not been previously recognized. In these analyses, a woman's age, a Gail model component, was associated only with the risk of ER-positive breast cancer but not with the risk of ER-negative breast cancer. As a result, the Gail model appears to have the ability to predict differential breast cancer risk by receptor subgroup in postmenopausal women. ${ }^{12,13}$

The Breast Cancer Risk Assessment tool is an interactive tool designed by scientists at the National Cancer Institute (NCI) and the National Surgical Adjuvant Breast and Bowel Project (NSABP) to estimate a woman's risk of developing invasive breast cancer. The tool can be accessed at www.cancer.gov/bcrisktool.

\section{Mammographic density}

Mammographic density refers to radiologically dense breast tissue, and reflects variations in the tissue composition of the breast. It is also a risk factor, with an increase in RR by a factor of 5 for the highest density. ${ }^{14,15}$ Similar and statistically significant trends between increased or decreased density and increased or decreased risk of breast cancer, respectively, are observed for women whose breast density category is initially 2 or 3 and changes categories. High mammographic density on the first examination is associated with a high rate of breast cancer (eg, about 10 per 1000 women), which remains high even if breast density decreases over continued observation. ${ }^{16}$

\section{Risk assessment strategies for postmenopausal women}

The Gail model works well for high-risk women, but other models may be required for women at only slightly increased risk or for whom age is the most important determinant of 
their risk. Significant risk factors for breast cancer diagnosis among premenopausal women include age, breast density, family history of breast cancer, and a prior breast procedure. Risk prediction models for breast cancer can be improved by incorporating breast density and current use of hormone therapy. A new risk prediction model predicts higher risks than the Gail model for women with a high percentage of dense breast area. ${ }^{17}$ The model also includes age, race, ethnicity, family history of breast cancer, a prior breast procedure, body mass index, natural menopause, hormone therapy, and a prior false-positive mammogram. The average risk projections from the new model in various age groups are similar to those from the Gail model, suggesting that the new model is well calibrated. This new model for absolute invasive breast cancer risk in white women promises modest improvements in discriminatory power compared with the Gail model.

The newer risk model may be better able to identify women at high risk for breast cancer for either preventive interventions or more intensive surveillance. Strategies for ER-positive breast cancer risk reduction in postmenopausal women require screening of large populations to identify those with potential benefit. ${ }^{12}$ Age and age at menopause are statistically significantly associated with ER-positive but not ER-negative cancers. For ER-positive cancers, no additional risk factors substantially improve the Gail model prediction. The simpler model that includes only age, breast cancer in first-degree relatives, and previous breast biopsy examination performs similarly for ER-positive breast cancer prediction. In postmenopausal women, the Gail model identified populations at increased risk for ER-positive but not ERnegative breast cancers. Risk can be quantified rapidly and simply by assessing the number and degree of a woman's relatives affected with breast cancer and their ages at diagnosis. A tabular version of this model is shown in Table 1 .

\section{Prevention of breast cancer in postmenopausal women: approaches to estimating and reducing risk Summary of the tamoxifen chemoprevention trials}

Data from four trials concluded that tamoxifen decreased breast cancer incidence by $38 \%{ }^{18}$ (Table 2). The risk reduction for development of ER-positive breast cancers was $48 \%$. No significant risk reduction was seen in the incidence of ER-negative breast cancers. Venous thromboembolic events were found to be nearly doubled in women using
Table I Predicted 5-year risk (\%) of estrogen receptor-positive invasive breast cancer in postmenopausal women ${ }^{12}$

\begin{tabular}{|c|c|c|c|}
\hline Age (years) & No biopsy & I biopsy & $>$ I biopsy \\
\hline \multicolumn{4}{|c|}{ No first-degree relative with breast cancer } \\
\hline \multicolumn{4}{|c|}{ All postmenopausal women } \\
\hline $50-54$ & 1.0 & 1.6 & 1.8 \\
\hline $55-59$ & 1.3 & 2.0 & 2.3 \\
\hline $60-64$ & 1.6 & 2.4 & 2.7 \\
\hline $65-69$ & 1.7 & 2.5 & 2.9 \\
\hline $70-74$ & 1.9 & 2.8 & 3.2 \\
\hline$\geq 75$ & 1.9 & 2.8 & 3.2 \\
\hline \multicolumn{4}{|c|}{ African American postmenopausal women } \\
\hline $50-54$ & 0.7 & 1.2 & 2.2 \\
\hline $55-59$ & 0.6 & 1.0 & 1.8 \\
\hline $60-64$ & 1.1 & 1.7 & 3.2 \\
\hline $65-69$ & 1.2 & 1.9 & 3.6 \\
\hline $70-74$ & 0.9 & 1.4 & 2.6 \\
\hline$\geq 75$ & 0.8 & 1.3 & 2.3 \\
\hline \multicolumn{4}{|c|}{$\geq$ I first-degree relative with breast cancer } \\
\hline \multicolumn{4}{|c|}{ All postmenopausal women } \\
\hline $50-54$ & 1.5 & .3 & 2.6 \\
\hline $55-59$ & 2.0 & 2.9 & 3.4 \\
\hline $60-64$ & 2.3 & 0.4 & 4.0 \\
\hline $65-69$ & 2.5 & 3.7 & 4.3 \\
\hline $70-74$ & 2.7 & 4.1 & 4.7 \\
\hline$\geq 75$ & 2.8 & 4.1 & 4.7 \\
\hline \multicolumn{4}{|c|}{ African American postmenopausal women } \\
\hline $50-54$ & 1.0 & 1.7 & 3.1 \\
\hline $55-59$ & 0.8 & 1.4 & 2.6 \\
\hline $60-64$ & 1.5 & 2.5 & 4.5 \\
\hline $65-69$ & 1.7 & 2.7 & 50 \\
\hline $70-74$ & 1.2 & 2.0 & 3.7 \\
\hline$\geq 75$ & I.I & 1.8 & 3.3 \\
\hline
\end{tabular}

Adapted from Chlebowski RT et al. Women's Health Initiative Investigators. Predicting risk of breast cancer in postmenopausal women by hormone receptor. J Natl Cancer Inst. 2007;99:1695-1705, by permission of Oxford University Press and National Cancer Institute (US).

tamoxifen in all trials with reduction in this risk seen with concomitant use of low dose aspirin. Rates of endometrial cancer were also found to be increased in all trials in women using tamoxifen, with a reduction in this risk seen by excluding women at increased risk of endometrial cancer, and higher risks in women over the age of 50 years. Overall, there was no effect on mortality from all causes; however, these trials were not powered or designed to analyze all-cause mortality events.

\section{Reduction of breast cancer incidence with raloxifene}

A number of clinical trials have been conducted to assess the benefit of raloxifene on osteoporosis and fracture and are listed in Table 3. After the publication of the results of the Breast Cancer Prevention Trial (BCPT), several osteoporosis trials also reported data related to the incidence of invasive 
Table 2 Summary of four randomized chemoprevention trials of tamoxifen ( $20 \mathrm{mg}$ per day vs placebo) for women at increased risk for breast cancer

\begin{tabular}{|c|c|c|c|c|}
\hline & $\begin{array}{l}\text { Breast Cancer } \\
\text { Prevention } \\
\text { Trial }(\text { BCPT) } \\
\end{array}$ & $\begin{array}{l}\text { Italian tamoxifen } \\
\text { prevention } \\
\text { study }^{21-23}\end{array}$ & $\begin{array}{l}\text { International Breast } \\
\text { Intervention } \\
\text { Study I (IBIS I) }\end{array}$ & $\begin{array}{l}\text { Royal Marsden hospital } \\
\text { chemoprevention trial }{ }^{26}\end{array}$ \\
\hline Number of subjects & $n=13,388$ & $\mathrm{n}=5408$ & $\mathrm{n}=7152$ & $\mathrm{n}=2494$ \\
\hline Subjects & $\begin{array}{l}\text { High breast cancer risk } \\
\text { (age } \geq 60 \text { years or a } \\
\text { combination of risk factors } \\
\text { using the Gail model); } \\
39 \%<50 \text { years; } \\
\geq 1.66 \% 5 \text {-yr risk }\end{array}$ & $\begin{array}{l}\text { Women with hysterectomy } \\
\text { ( } 48 \% \text { bilateral oophorectomy); } \\
\text { Median age: } 5 \text { I years }\end{array}$ & $\begin{array}{l}\text { Women aged } 35 \text { to } \\
70 \text { years who were at } \\
\text { increased risk for } \\
\text { breast cancer; } \\
>2 \text { fold relative risk }\end{array}$ & $\begin{array}{l}\text { Family history of breast } \\
\text { cancer }<50 \text { years old } \\
\text { or } 2 \text { or more affected } \\
\text { first-degree relatives }\end{array}$ \\
\hline $\begin{array}{l}\text { Median follow-up, } \\
\text { years }\end{array}$ & 7 & II & 8 & 13 \\
\hline Invasive breast & Placebo: 250 & Placebo: 74 & Placebo: 168 & Placebo: 82 \\
\hline cancers & Tamoxifen: I45 & Tamoxifen: 62 & Tamoxifen: I24 & Tamoxifen: 104 \\
\hline Breast cancer & Invasive & All cases & Invasive & All cases \\
\hline relative risks and & RR: $0.57(0.46-0.70)$ & RR: 0.84 (0.60-I.I7) & RR: $0.74(0.58-0.94)$ & RR: $0.78(0.58-1.04)$ \\
\hline$(95 \% \mathrm{Cl})$ & $\begin{array}{l}\text { Noninvasive } \\
\text { RR: } 0.63(0.45-0.89)\end{array}$ & $\begin{array}{l}\text { High-risk group: } \\
\text { RR: } 0.2(0.10-0.59)\end{array}$ & $\begin{array}{l}\text { DCIS } \\
\text { RR: } 0.63(0.32-1.2)\end{array}$ & \\
\hline Risk reduction & $\begin{array}{l}\text { Invasive } 43 \% \\
\text { DCIS, LCIS } 37 \% \\
\text { With prior LCIS } 46 \% \\
\text { With prior atypical } \\
\text { hyperplasia }\end{array}$ & $\begin{array}{l}\text { Overall: no reduction; } \\
\text { in the high-risk subset: } 82 \%\end{array}$ & $\begin{array}{l}\text { Overall: } 27 \% \\
\text { DCIS: } 37 \%\end{array}$ & $\begin{array}{l}\text { Overall: no reduction } \\
\text { post-treatment period: } \\
\text { invasive: } 37 \% \\
\text { ER(+): } 52 \%\end{array}$ \\
\hline
\end{tabular}

Abbreviations: DCIS, ductal carcinoma in situ; ER, estrogen receptor; LCIS, lobular carcinoma in situ; RR, relative risk.

breast cancer among women taking raloxifene compared with those taking placebo.

The Multiple Outcomes of Raloxifene Evaluation (MORE) trial randomized 7705 postmenopausal women younger than 81 years (mean age $=66.5$ years) with osteoporosis to raloxifene or placebo. ${ }^{27,28}$ The primary aim of the MORE study was to test whether 3 years of raloxifene reduced the risk of fracture in postmenopausal women with osteoporosis, and the occurrence of breast cancer was a secondary endpoint. With a median follow-up of 40 months, raloxifene reduced the risk of invasive breast cancer by $76 \%$ in postmenopausal women with osteoporosis, largely accounted for by a $90 \%$ reduction in ER-positive breast cancer. Raloxifene did not reduce the risk of ER-negative breast cancer.

The Continuing Outcomes Relevant to Evista (CORE) trial was designed to evaluate the efficacy of an additional 4 years of raloxifene therapy in preventing invasive breast cancer in women who participated in the MORE trial. ${ }^{29}$ CORE was a multicenter, double-blind, placebo-controlled clinical trial. The CORE trial was conducted in the subset of the MORE women who agreed to participate in what was an extension of the MORE trial, with a change in the primary endpoint from vertebral fracture incidence to invasive breast cancer. A secondary objective of the CORE trial was to examine the effect of raloxifene (at $60 \mathrm{mg} /$ day) on the incidence of invasive ER-positive breast cancer. Women in the raloxifene group had a $59 \%$ reduction in the incidence of all invasive breast cancer compared with women in the placebo group and a $66 \%$ reduction in the incidence of invasive ER-positive breast cancers compared with women in the placebo group. The raloxifene group had a $66 \%$ reduction in the incidence of invasive breast cancer compared with the placebo group, and by 8 years, the raloxifene group had a $76 \%$ reduction in the incidence of invasive ER-positive breast cancer compared with the placebo group. There was no difference in the incidence rates of invasive ER-negative breast cancer between the raloxifene group and the placebo group. During the 8 years of the MORE and CORE trials, the overall incidence of breast cancer, both in situ and invasive, was reduced by $58 \%$ in the raloxifene group compared with the placebo group.

The Raloxifene Use for The Heart (RUTH) trial was a randomized, double-blind, placebo-controlled trial whose primary objectives were to determine the effect of raloxifene compared with placebo on the incidence of both coronary events and invasive breast cancer. ${ }^{30}$ A total of 10,101 postmenopausal women with coronary heart disease or at increased risk for coronary heart disease were randomized to raloxifene $60 \mathrm{mg}$ /daily or placebo and followed for a median 
Table 3 Prospective, randomized, placebo-controlled clinical studies of raloxifene with invasive breast cancer as an endpoint

\begin{tabular}{|c|c|c|c|c|}
\hline Study & MORE ${ }^{27,28}$ & CORE $^{29}$ & RUTH ${ }^{30}$ & STAR $^{31,32}$ \\
\hline Number of subjects & $\mathrm{n}=7705$ & $\mathrm{n}=5213$ & $\mathrm{n}=10,101$ & $n=19,747$ \\
\hline $\begin{array}{l}\text { Mean age/ } \\
\text { study population }\end{array}$ & $\begin{array}{l}66.5 / \text { with at least one } \\
\text { osteoporotic fracture }\end{array}$ & $\begin{array}{l}66.2 / \text { continuation } \\
\text { of the MORE study }\end{array}$ & $\begin{array}{l}\text { 67.5/with a history of } \\
\text { CHD or risk factors for CHD }\end{array}$ & $\begin{array}{l}\text { 58.5/postmenopausal women: } \\
\text { increased risk of breast cancer }\end{array}$ \\
\hline Primary outcome & Fractures & Fractures & $\begin{array}{l}\mathrm{CHD} \text { events and } \\
\text { invasive breast cancer }\end{array}$ & Invasive breast cancer \\
\hline Secondary outcomes & Breast cancer & Breast cancer & Death & Fracture, $\mathrm{CHD}$ events \\
\hline Major toxicities reported & $\begin{array}{l}\text { Thromboembolic events, } \\
\text { uterine malignancy }\end{array}$ & $\begin{array}{l}\text { Thromboembolic events, } \\
\text { uterine malignancy }\end{array}$ & $\begin{array}{l}\text { Thromboembolic events, } \\
\text { uterine malignancy }\end{array}$ & $\begin{array}{l}\text { Thromboembolic events, } \\
\text { uterine malignancy, } \\
\text { other cancers, total deaths }\end{array}$ \\
\hline Formal quality of life study & No & No & No & Yes \\
\hline $\begin{array}{l}\text { Event rate in the } \\
\text { raloxifene group } \\
\text { (per } 1000 \text { woman-years) }\end{array}$ & 0.9 & 1.4 & 1.5 & 4.4 \\
\hline $\begin{array}{l}\text { No. of breast cancers } \\
\text { in the comparison group }\end{array}$ & 27 & 58 & 533 & 163 \\
\hline $\begin{array}{l}\text { Event rate in the } \\
\text { comparison group } \\
\text { (per } 1000 \text { woman-years) }\end{array}$ & 3.6 & 4.2 & 2.7 & 4.3 \\
\hline Risk reduction & $24 \%$ & $34 \%$ & $56 \%$ & $\begin{array}{l}\text { Not applicable } \\
\text { (no placebo group) }\end{array}$ \\
\hline
\end{tabular}

Adapted from Vogel VG. Raloxifene: a second-generation selective estrogen receptor modulator for reducing the risk of invasive breast cancer in postmenopausal women. Women's Health. 2007;3:139-153. ${ }^{37}$ With permission from Future Medicine Ltd.

Abbreviation: CHD, coronary heart disease.

of 5.6 years. There was a $44 \%$ decreased incidence of invasive breast cancer in the raloxifene group caused primarily by a reduction in ER-positive invasive breast cancers with a 55\% decrease in the raloxifene group. There was no significant difference, however, between treatment groups in the incidence of ER-negative invasive breast cancers.

\section{Study of tamoxifen and raloxifene}

The National Surgical Adjuvant Breast and Bowel Project (NSABP) Study of Tamoxifen and Raloxifene (STAR) trial was launched to compare tamoxifen with raloxifene in a population of women at increased risk for breast cancer. The trial was conducted in nearly 200 clinical centers throughout North America. A total of 19,747 postmenopausal women were randomly assigned to receive either tamoxifen or raloxifene $(60 \mathrm{mg} / \mathrm{d})$ for a maximum of 5 years. To be eligible for participation in the STAR trial, a woman had to have at least a 5 -year predicted breast cancer risk of $1.66 \%$ based on the Gail model and be at least 35 years of age and postmenopausal. Postmenopausal women aged 35 years and older could enter the trial if they had a history of LCIS treated by local excision alone. The mean age of participants at the time of randomization was 58.5 years. The mean predicted 5 -year risk of developing breast cancer among the study population was $4.03 \%$. The mean time of follow-up was 3.9 years when the trial was initially reported. ${ }^{31}$
The primary endpoint was invasive breast cancer. Secondary endpoints included endometrial cancer, in situ breast cancer, cardiovascular disease (myocardial infarction, severe angina, acute ischemic syndrome), stroke, pulmonary embolism, deep vein thrombosis, transient ischemic attack, osteoporotic fracture, cataracts, death, and quality of life. In the initial report, there was no difference between the effect of tamoxifen and the effect of raloxifene on the incidence of invasive breast cancer. After a median of 3.2 years of therapy in the STAR trial, there were 163 cases of invasive breast cancer in women assigned to tamoxifen and 168 in those assigned to raloxifene. The cumulative incidence through 72 months for the two treatment groups was 25.1 and 24.8 per 1000 for the tamoxifen and raloxifene groups, respectively. When the treatment groups were compared by baseline categories of age, history of LCIS, history of atypical hyperplasia, Gail model 5-year predicted risk of breast cancer, and the number of relatives with a history of breast cancer, the pattern of no differential effect by treatment assignment remained consistent. There were no differences between the treatment groups with regard to distributions by tumor size, nodal status, or ER level.

In contrast to the findings for invasive breast cancer, there were fewer noninvasive breast cancers in the tamoxifen group than in the raloxifene group although this difference did not reach statistical significance. There were 57 cases 
of noninvasive breast cancer in the tamoxifen group and 80 among the raloxifene group. There was a trend toward a decreased incidence of uterine cancer in the raloxifene group, but the difference was not statistically significant -36 cases in the tamoxifen group compared with 23 in the raloxifene group (RR: 0.62).

For ischemic heart disease events, there were 114 events in the tamoxifen group and 126 events in the raloxifene group. This difference was not statistically significant. The difference in total number of strokes was small, with the number of events occurring in women assigned to tamoxifen being only two more than in those assigned to raloxifene (53 vs 51). There was no statistically significant difference between tamoxifen and raloxifene in the number of transient ischemic attacks that occurred (41 in the tamoxifen group vs 50 in the raloxifene group; RR: 1.21). However, there was a statistically significant difference between the treatment groups for the incidence of thromboembolic events, with the raloxifene group experiencing fewer cases of pulmonary embolism and deep venous thrombosis. Overall, there were 141 events with tamoxifen and 100 with raloxifene, indicating that the risk was $30 \%$ less in the raloxifene group (RR: 0.70). Pulmonary embolism and deep vein thrombosis occurred in 54 vs 35 women (RR: 0.64) and in 87 vs 65 women (RR: 0.74) assigned to tamoxifen and raloxifene, respectively.

An updated analysis of the STAR trial results was done with an 81-month median follow-up. ${ }^{32}$ The risk ratio (raloxifene:tamoxifen) for invasive breast cancer was 1.24 and for noninvasive disease, 1.22. Compared with initial results, the RRs widened for invasive and narrowed for

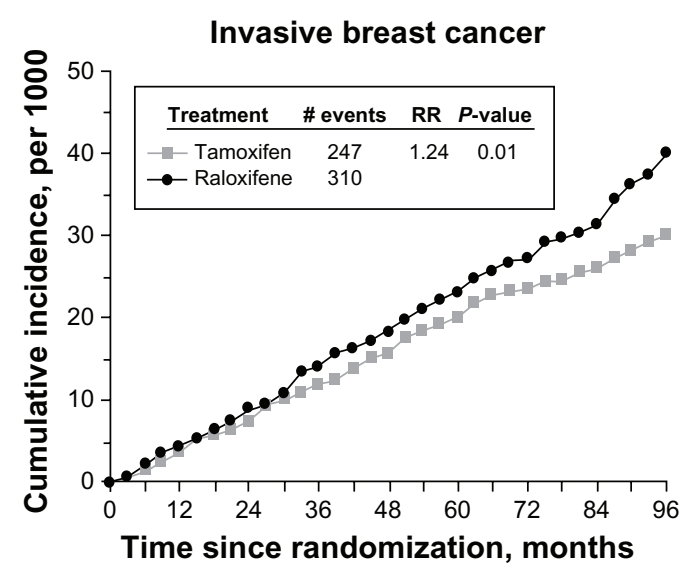

No. at risk

$\begin{array}{llllllll}\text { Raloxifene } & 9754 & 9398 & 8973 & 8196 & 5999 & 4453 & 2650\end{array}$

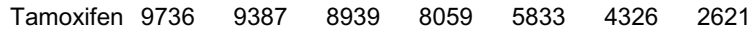

noninvasive breast cancer. These data are shown graphically in Figure 1. Toxicity RRs (raloxifene:tamoxifen) were 0.55 for endometrial cancer, 0.19 for uterine hyperplasia, and 0.75 for thromboembolic events. There were no significant mortality differences. Long-term raloxifene retained $76 \%$ of the effectiveness of tamoxifen in preventing invasive disease and grew closer over time to tamoxifen in preventing noninvasive disease, with far less toxicity (eg, highly significantly less endometrial cancer). These results have important public health implications and clarify that both raloxifene and tamoxifen are good preventive choices for postmenopausal women with elevated risk for breast cancer.

\section{Noninvasive breast cancer in the NSABP STAR trial}

In the STAR trial, there were fewer noninvasive breast cancers in the tamoxifen group than in the raloxifene group, although this difference did not initially reach statistical significance. In the initial report there were 57 incident cases of noninvasive breast cancer among the women who took tamoxifen and 80 among the women who took raloxifene. In the 81-month analysis of the STAR trial, the RR for noninvasive disease was $1.22 .^{32}$ Patients with a history of LCIS or atypical hyperplasia of the breast have a four-fold to ten-fold increased risk of subsequent invasive disease, and tamoxifen and raloxifene were equally effective in reducing this risk in the initially reported STAR results. The analyses at 81 months indicated that this equality was no longer the case for STAR women with a history of atypical hyperplasia (RR: 1.48), although results for the LCIS group remain similar to those reported originally (RR: 1.13).

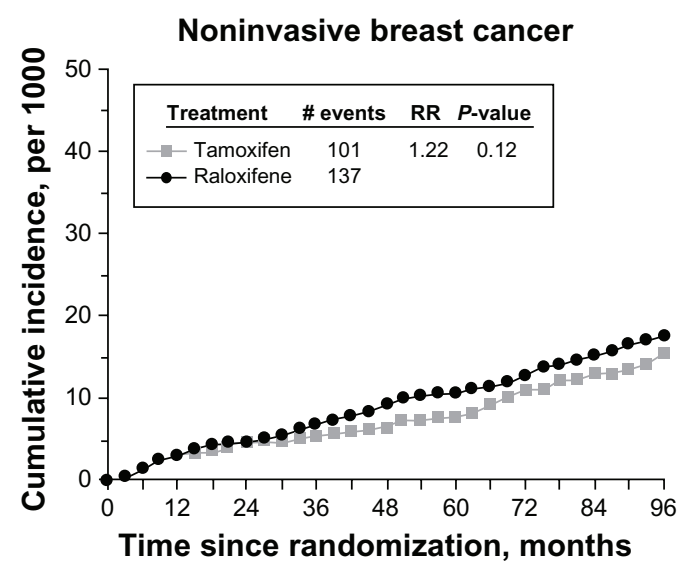

No. at risk

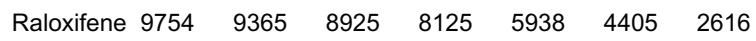

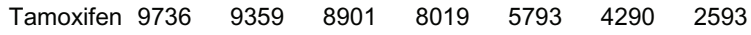

Figure I Cumulative incidences of invasive and noninvasive breast cancer. 


\section{Quality of life with raloxifene}

In all of the tamoxifen prevention trials that compare tamoxifen with placebo, there was a statistically significant increase in vasomotor and gynecologic symptoms. There was no significant difference in weight gain or depression scores between the two arms in those studies that reported on them. The NSABP BCPT noted that women on tamoxifen reported a small but significant increase in problems related to sexual functioning compared with those on placebo, although the overall frequency of sexual activity was similar in the two groups.

In the STAR trial there were no significant differences between tamoxifen and raloxifene in participant-reported outcomes for physical and mental health. ${ }^{33}$ As noted above, the initial report of the STAR trial demonstrated that raloxifene and tamoxifen were equivalent in efficacy for lowering the risk of invasive breast cancer. Consistent with results from other large scale trials, raloxifene compared with placebo does not increase endometrial cancer risk. Statistically significant differences in the average mean severity of individual quality-of-life measures between the two arms were observed, however. An increase in gynecologic symptoms, vasomotor symptoms, leg cramps, and bladder control problems was observed in both groups during treatment, with the difference being significantly greater for the tamoxifen group compared with the raloxifene group. In contrast, women in the raloxifene group reported significantly more musculoskeletal problems, dyspareunia, and weight gain. Despite being statistically significant, these differences were associated with small effect sizes. Hot flashes and leg cramps, but not peripheral edema, were also more

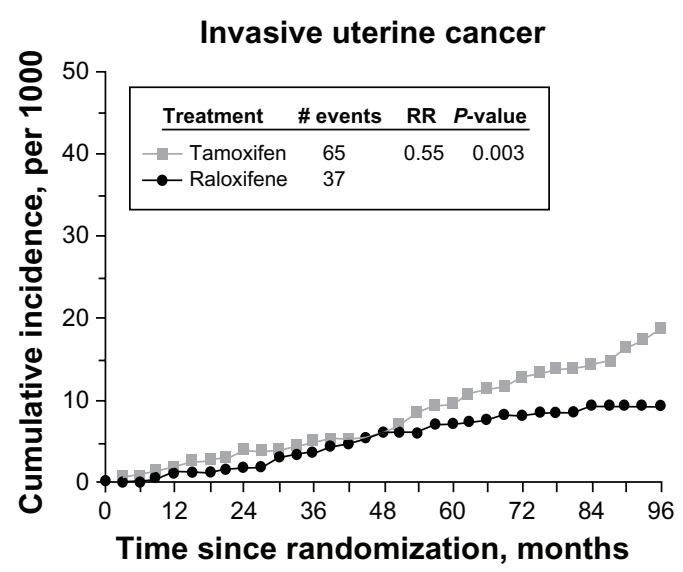

No. at risk

$\begin{array}{llllllll}\text { Raloxifene } & 4717 & 4556 & 4368 & 3976 & 2913 & 2157 & 1295\end{array}$

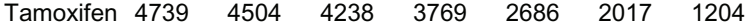

common in the raloxifene arm compared with the placebo arm. These findings illustrate that potential adverse effects on components of quality of life should be considered when discussing risk reduction options.

The superiority of tamoxifen over raloxifene in reducing breast cancer risk is associated with significantly more endometrial cancers, hysterectomies for benign and malignant disease, and thromboembolic events (Figure 2 and Table 4). These toxicities may be acceptable for the treatment of breast cancer but are barriers to its use for preventing primary breast cancers. The data also demonstrate that raloxifene retains substantial benefit in reducing the risk of invasive breast cancer with fewer life-threatening side effects than tamoxifen, including significantly fewer endometrial cancers, which is in keeping with the placebo-controlled raloxifene trials.

\section{Summary of the benefits of SERMs for reducing the risk of breast cancer}

For postmenopausal women with elevated risk, the results reviewed herein should encourage widespread acceptance of raloxifene for breast cancer risk reduction, especially among women with an intact uterus who also face a risk of osteoporosis and fracture. Such increased acceptance of SERMs for breast cancer risk reduction ultimately would reduce the public health burden of the disease.

Raloxifene will prevent 15 invasive and 16 noninvasive breast cancers over 7 years in 1000 women at an elevated risk (4\%) vs causing 2.47 thromboembolic events and no endometrial cancers in the same group over 7 years. ${ }^{34}$ For these major effects, tamoxifen causes 40 beneficial vs 5.5 adverse effects (benefit/risk ratio of about 7:1) and raloxifene

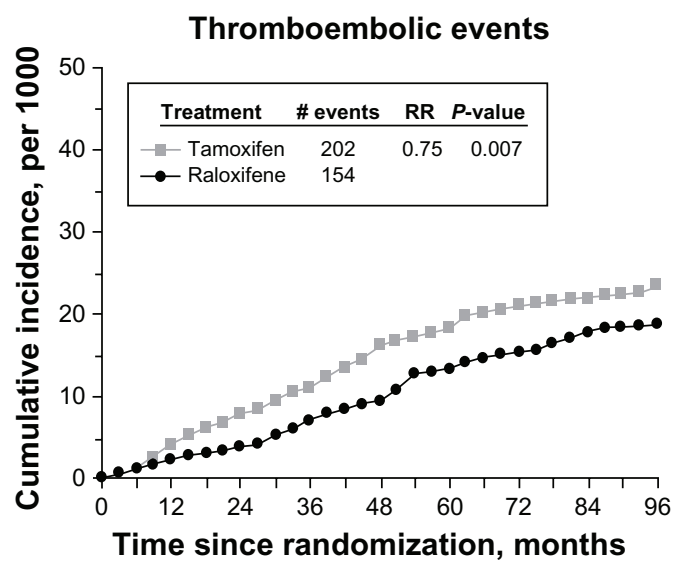

No. at risk

$\begin{array}{lllllll}\text { Raloxifene } 9754 & 9439 & 9049 & 8277 & 6079 & 4515 & 2706\end{array}$

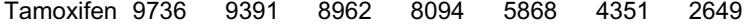

Figure 2 Cumulative incidences of invasive uterine cancer and thromboembolic events. 
Table 4 Annual rates of noninvasive breast cancer and uterine disease/hysterectomy in the NSABP STAR Trial ${ }^{32}$

\begin{tabular}{|c|c|c|c|c|c|c|}
\hline \multirow[t]{2}{*}{ Disease type } & \multicolumn{2}{|l|}{ Events (n) } & \multicolumn{2}{|c|}{ Rate per 1,000} & \multirow[t]{2}{*}{ Difference } & \multirow[t]{2}{*}{ Relative risk } \\
\hline & Tamoxifen & Raloxifene & Tamoxifen & Raloxifene & & \\
\hline \multicolumn{7}{|l|}{ Noninvasive breast cancer } \\
\hline DCIS & 70 & 86 & 1.15 & 1.40 & -0.25 & 1.22 \\
\hline LCIS & 33 & 34 & 0.54 & 0.55 & -0.01 & 1.02 \\
\hline Mixed & 8 & 17 & 0.13 & 0.58 & -0.15 & 2.11 \\
\hline Total & 111 & 137 & 1.83 & 2.23 & -0.40 & 1.22 \\
\hline \multicolumn{7}{|l|}{ Uterine disease and hysterectomy } \\
\hline Invasive cancer & 65 & 37 & 2.25 & 1.23 & 1.02 & 0.55 \\
\hline Hyperplasia & 126 & 25 & 4.40 & 0.84 & 3.56 & 0.19 \\
\hline Without atypia & 104 & 21 & 3.63 & 0.70 & 2.93 & 0.19 \\
\hline With atypia & 22 & 4 & 0.77 & 0.13 & 0.64 & 0.17 \\
\hline Hysterectomy during follow-up & 349 & 162 & 12.08 & 5.41 & 6.67 & 0.45 \\
\hline
\end{tabular}

Abbreviations: DCIS, ductal carcinoma in situ; LCIS, lobular carcinoma in situ.

causes 31 beneficial vs 2.5 adverse effects (benefit/risk ratio of about 13:1) over 7 years. These ratios indicate a rather extraordinary net gain for women at a $4 \% 5$-year risk of breast cancer and would improve substantially for women at a $4 \%$ or higher risk, who number approximately 600,000 in the US. These numbers also suggest that women at considerably lower risks (between 1.67\% and 4\%) would still have a positive benefit/risk ratio with raloxifene.

\section{Chemoprevention options for breast cancer risk reduction}

On the basis of the results of the STAR Trial, the US Food and Drug Administration approved raloxifene for the reduction of breast cancer risk in women whose risk of developing breast cancer is equal to the minimum eligibility for the trial, that is, a probability of developing breast cancer of $1.66 \%$ or greater in 5 years as determined by the Gail model. The results of the STAR trial argue in favor of using raloxifene rather than tamoxifen for reducing the risk of breast cancer in postmenopausal women because of the lack of uterine effect with raloxifene and the much more favorable risk of thromboembolic events.

The use of any SERM for the reduction of breast cancer risk requires consideration of a woman's absolute risk of breast cancer as determined by quantitative modeling, or the presence of risk factors themselves known to increase the risk of breast cancer substantially (eg, LCIS) as summarized in Table 5. It is also necessary to evaluate risk/benefit considerations including the absolute reduction in the risk of breast cancer that is expected to accrue with the use of raloxifene. A strategy to weigh risks and benefits of SERM therapy in the setting of breast cancer risk reduction in a semi-quantitative manner has been described. ${ }^{35}$ The risk of developing breast cancer is the primary determinant of net benefit, with greater net benefits accruing to women with the highest risk of breast cancer. Both age and the presence of factors that increase the risk of toxicity have the greatest effect on the net benefit associated with raloxifene.

As noted previously, one can use the Breast Cancer Risk Assessment Tool developed by the US NCI to estimate the projected 5-year risk of breast cancer based on a woman's breast cancer risk factors. The use of a SERM should not be based solely on a single number, such as a projected 5-year risk of breast cancer of $1.66 \%$, but rather it should be based on a weighing of the various risks and benefits of the drug. For older women at higher risk of endometrial cancer, stroke, and pulmonary embolism, higher levels of projected 5-year risk of breast cancer would be needed to justify the use of tamoxifen. Raloxifene, on the other hand, offers significant benefit because of its lack of effect on the uterus of a postmenopausal woman.

Women at elevated or high risk of developing breast cancer are those who have an RR of 1.5-five-fold. Women in this group include those with a 5-year Gail risk greater than $1.7 \%$, those with a finding of atypical ductal or

Table 5 Postmenopausal women who are candidates for the use of raloxifene to reduce their risk of breast cancer*

\begin{tabular}{ll}
\hline Risk factor & Risk increase \\
\hline Gail model score $>1.6 \%$ in 5 years & 2 to 4 -fold \\
Atypical ductal or lobular hyperplasia & $\begin{array}{l}5 \text {-fold (or greater with a } \\
\text { family history) }\end{array}$ \\
Lobular carcinoma in situ & 10 -fold (I\% to $2 \%$ annual risk) \\
High mammographic density & 2 to 4 -fold \\
Combination of age $>55$ years, & $\geq 2 \%$ in 5 years \\
family history and breast biopsy & \\
\hline
\end{tabular}

Note: *Women with osteoporosis and any breast cancer risk factors derive dual benefit from raloxifene. 
lobular hyperplasia on breast biopsy; women with cellular atypia or LCIS; women with two or more second-degree premenopausal relatives affected with breast cancer; and women who have been taking combined estrogen and progesterone hormone replacement therapy (HRT) for more than 10 years. Women with biopsy-proven atypical ductal or lobular hyperplasia have a four-fold to five-fold increased risk of developing breast cancer in the ensuing 20 years. Women with a 5-year Gail risk greater than 1.7\% have at least a twofold greater risk than women at average risk, and this may be considerably higher depending on the number of first-degree relatives affected, and whether the woman is known to have atypical hyperplasia.

Published indications for the use of raloxifene for the reduction of breast cancer risk include an increased quantitative risk of breast cancer, the presence of LCIS, a diagnosis of atypical hyperplasia plus a family history of breast cancer in first-degree relatives, or the presence of osteoporosis and an increased risk of breast cancer. ${ }^{36}$ Absolute contraindications to the use of raloxifene for breast cancer risk reduction include a history of deep venous thrombosis or pulmonary embolism, a history of stroke or transient ischemic attack, a history of uncontrolled diabetes or hypertension (because of the increased risk of stroke), and/or a history of uncontrolled atrial fibrillation. Clinicians are strongly cautioned, however, to consider the risk-benefit balance in women at risk for stroke. Those women currently taking estrogen, progesterone, androgens, or birth control pills should discontinue these medications before initiating SERM therapy. It should be used with caution in the setting of immobilization, including patients in postsurgical recovery, those at prolonged bed rest, and women with prolonged travel itineraries. Finally, raloxifene should also be used cautiously or not at all in women who are at increased risk of venous thromboembolic events including those with congestive heart failure, superficial thrombophlebitis, obese women, and in those with active malignancy.

Management of women at increased risk for breast cancer should include comprehensive quantitative risk assessment, counseling appropriate to the individual's risk, the opportunity for genetic testing where appropriate, and a specific management prescription. ${ }^{35,36}$ The counseling process should be interactive and sensitive to the patient's educational level and cultural background. Women who are actively involved in decision-making are more satisfied with their decisions and more informed. Because an individual's preferences and risk status can change substantially over time, it is also important that decisions about tamoxifen not be regarded as either urgent or irreversible. The patient's perception of her own risk should be elicited so that it can be compared with an objective risk estimate. This discussion might include her personal experience of breast cancer in family members and her beliefs and fears concerning cancer etiology and treatment. Clinicians should strive to ensure that the patient understands her objective risk and its implications for making a decision about the use of raloxifene.

\section{Limitations in using raloxifene for reduction of breast cancer risk}

The optimal duration of risk-reducing therapy is not known, and whether using tamoxifen or raloxifene for longer than 5 years is more effective than only 5 years, to prevent the recurrence of breast cancer is the subject of ongoing clinical trials. The current recommendation is that raloxifene should be used for at least 5 years to reduce the risk of breast cancer. Making a commitment to 5 years of SERM therapy is not easy because several potentially severe adverse reactions can be associated with this therapy as we have seen, and the optimal age at which to start therapy is unknown.

Raloxifene has similar risk reduction activity when compared with tamoxifen but has less toxicity, particularly in the uterus, making it a more attractive option than tamoxifen for use as a breast cancer risk reduction agent in postmenopausal healthy women. Published clinical trials demonstrate that the greatest clinical benefit, with the fewest side effects, occurs in high-risk, younger, postmenopausal women. In this population of women, raloxifene appears to offer net benefit when comparing reduction of the risk of breast cancer and the prevention of fractures with the risk of stroke, venous thromboembolic events, uterine events, and symptomatic side effects. An enormous net benefit with the use of the SERMs is also seen in women with LCIS and atypical ductal or lobular hyperplasia.

\section{Summary recommendation}

For postmenopausal women at increased risk for breast cancer, raloxifene ( $60 \mathrm{mg}$ /day) for 5 years may be offered as an option to reduce the risk of ER-positive invasive breast cancer. Raloxifene is not as efficacious as tamoxifen in reducing breast cancer risk in postmenopausal women. However, raloxifene is associated with a more favorable side-effect profile compared with tamoxifen, including a statistically significant lower risk of thromboembolic disease, benign uterine complaints, and cataracts. Raloxifene, like tamoxifen, is not known to have an effect on overall or breast cancer-specific mortality in women at increased risk of breast cancer. 
However, the risk reduction trials were powered to detect a reduction in breast cancer incidence, rather than mortality, as it was felt to be an important endpoint in and of itself. Raloxifene may be used for longer than 5 years in women with osteoporosis in whom breast cancer risk reduction is an additional potential benefit. Raloxifene is not recommended in premenopausal women or in women with a prior history of deep venous thrombosis, pulmonary embolism, stroke, or transient ischemic attack. In postmenopausal women, the risks and benefits of raloxifene, including risks of noninvasive breast cancer, adverse events, and impact on quality of life, should be discussed in detail with women before coming to a decision about initiating a risk reduction strategy.

\section{Disclosure}

The author reports no conflicts of interest in this work.

\section{References}

1. Vogel VG. Managing the risk of breast cancer in postmenopausal women: introduction. Menopause. 2008;15(4 Suppl):779-781.

2. Gierach G, Vogel VG. Epidemiology of breast cancer. In: Singletary SE, Robb GL, Hortobagyi GN, editors. Advanced Therapy of Breast Disease. 2nd ed. Hamilton, ON: BC Decker, Inc; 2004:58-83.

3. Reeves K, Hudson A, Vogel VG. Epidemiology of breast cancer. In: Bland KI, Copeland EM, editors. The Breast: Comprehensive Management of Benign and Malignant Disease. 4th ed. Philadelphia, PA: Elsevier; 2009:349-369.

4. Velie EM, Nechuta S, Osuch JR. Lifetime reproductive and anthropometric risk factors for breast cancer in postmenopausal women. Breast Dis. 2005;24:17-35.

5. Santen RJ, Mansel R. Benign breast disorders. N Engl J Med. 2005;353: 275-285.

6. Hartmann LC, Sellers TA, Frost MH, et al. Benign breast disease and the risk of breast cancer. N Engl J Med. 2005;353:229-237.

7. Claus EB, Risch N, Thompson WD. Genetic analysis of breast cancer in the Cancer and Steroid Hormone Study. Am J Hum Genet. 1991;48: $232-242$.

8. Narod SA, Offit K. Hereditary breast cancer: prevention and management of hereditary breast cancer. J Clin Oncol. 2005;23:1656-1663.

9. Gail MH, Brinton LA, Byar DP, et al. Projecting individualized probabilities of developing breast cancer for white females who are being examined annually. J Natl Cancer Inst. 1989;81:1879-1886.

10. Costantino JP, Gail MH, Pee D. Validation studies for models projecting the risk of invasive and total breast cancer incidence. J Natl Cancer Inst. 1999;91:1541-1548.

11. Barlow WE, White E, Ballard-Barbash R, et al. Prospective breast cancer risk prediction model for women undergoing screening mammography. J Natl Cancer Inst. 2006;98:1204-1214.

12. Chlebowski RT, Anderson GL, Lane DS, et al. Women's Health Initiative Investigators. Predicting risk of breast cancer in postmenopausal women by hormone receptor. J Natl Cancer Inst. 2007;99: 1695-1705.

13. Cummings SR, Tice JA, Bauer S, et al. Prevention of breast cancer in postmenopausal women: approaches to estimating and reducing risk. J Natl Cancer Inst. 2009;101:384-398.

14. Tice JA, Cummings SR, Ziv E, Kerlikowske K. Mammographic breast density and the Gail model for breast cancer risk prediction in a screening population. Breast Cancer Res Treat. 2005;94:115-122.
15. Boyd NF, Martin LJ, Yaffe MJ, Minkin S. Mammographic density: a hormonally responsive risk factor for breast cancer. J Br Menopause Soc. 2006;12:186-193.

16. Kerlikowske K, Ichikawa L, Miglioretti DL, et al; National Institutes of Health Breast Cancer Surveillance Consortium. Longitudinal measurement of clinical mammographic breast density to improve estimation of breast cancer risk. J Natl Cancer Inst. 2007;99: 386-395.

17. Chen J, Pee D, Ayyagari R, et al. Projecting absolute invasive breast cancer risk in white women with a model that includes mammographic density. J Natl Cancer Inst. 2006;98:1215-1226.

18. Cuzick J, Powles T, Veronesi U, et al. Overview of the main outcomes in breast-cancer prevention trials. Lancet. 2003;361:296-300.

19. Fisher B, Costantino JP, Wickerham DL, et al. Tamoxifen for prevention of breast cancer: report of the National Surgical Adjuvant Breast and Bowel Project P-1 Study. J Natl Cancer Inst. 1998;90:1371-1388.

20. Fisher B, Costantino JP, Wickerham DL, et al. Tamoxifen for the prevention of breast cancer: current status of the National Surgical Adjuvant Breast and Bowel Project P-1study. J Natl Cancer Inst. 2005;97: 1652-1662.

21. Veronesi U, Maisonneuve P, Sacchini V, Rotmensz N, Boyle P; Italian Tamoxifen Study Group. Tamoxifen for breast cancer among hysterectomised women. Lancet. 2002;359:1122-1124.

22. Veronesi U, Maisonneuve P, Rotmensz N, et al; Italian Tamoxifen Study Group. Italian randomized trial among women with hysterectomy: tamoxifen and hormone-dependent breast cancer in high-risk women. J Natl Cancer Inst. 2003;95:160-165.

23. Veronesi U, Maisonneuve P, Rotmensz N, et al; Italian Tamoxifen Study Group. Tamoxifen for the prevention of breast cancer: late results of the Italian Randomized Tamoxifen Prevention Trial among women with hysterectomy. J Natl Cancer Inst. 2007;99:727-737.

24. Cuzick J, Forbes J, Edwards R, et al; IBIS investigators. First results from the International Breast Cancer Intervention Study (IBIS-I): a randomised prevention trial. Lancet. 2002;360:817-824.

25. Cuzick J, Forbes JF, Sestak I, et al; International Breast Cancer Intervention Study I Investigators. Long-term results of tamoxifen prophylaxis for breast cancer - 96-month follow-up of the randomized IBIS-I trial. J Natl Cancer Inst. 2007;99:272-282.

26. Powles TJ, Ashley S, Tidy A, Smith I, Dowsett M. Twenty-year follow-up of the Royal Marsden randomized, double-blinded Tamoxifen Breast Cancer Prevention Trial. J Natl Cancer Inst. 2007;99:283-290.

27. Cummings SR, Eckert S, Krueger KA, et al. The effect of raloxifene on risk of breast cancer in postmenopausal women: results from the MORE randomized trial. JAMA. 1999;281:2189-2197.

28. Cauley JA, Norton L, Lippman ME, et al. Continued breast cancer risk reduction in postmenopausal women treated with raloxifene: 4-year results from the MORE trial. Multiple outcomes of raloxifene evaluation. Breast Cancer Res Treat. 2001;65:125-134.

29. Martino S, Cauley JA, Barrett-Connor E, et al; CORE Investigators. Continuing outcomes relevant to Evista: breast cancer incidence in postmenopausal osteoporotic women in a randomized trial of raloxifene. J Natl Cancer Inst. 2004;96:1751-1761.

30. Barrett-Connor E, Mosca L, Collins P, et al; Raloxifene Use for The Heart (RUTH) Trial Investigators. Effects of raloxifene on cardiovascular events and breast cancer in postmenopausal women. N Engl J Med. 2006;355:125-137.

31. Vogel VG, Costantino JP, Wickerham DL, et al. National Surgical Adjuvant Breast and Bowel Project (NSABP). Effects of tamoxifen vs raloxifene on the risk of developing invasive breast cancer and other disease outcomes: the NSABP Study of Tamoxifen and Raloxifene (STAR) P-2 trial. JAMA. 2006;295:2727-2741.

32. Vogel VG, Costantino JP, Wickerham DL, et al. National Surgical Adjuvant Breast and Bowel Project. Update of the National Surgical Adjuvant Breast and Bowel Project Study of Tamoxifen and Raloxifene (STAR) P-2 Trial: preventing breast cancer. Cancer Prev Res. 2010;3: 696-706. 
33. Land SR, Wickerham DL, Costantino JP, et al. Patient-reported symptoms and quality of life during treatment with tamoxifen or raloxifene for breast cancer prevention: the NSABP Study of Tamoxifen and Raloxifene (STAR) P-2 trial. JAMA. 2006;295:2742-2751.

34. Hortobagyi GN, Brown PH. Two good choices to prevent breast cancer: great taste, less filling. Cancer Prev Res. 2010;3:681-685.

35. Vogel VG. The NSABP Study of Tamoxifen and Raloxifene (STAR) Trial. Expert Rev Anticancer Ther. 2009;9:51-60.
36. Visvanathan K, Chlebowski RT, Hurley P, et al; American Society of Clinical Oncology. American society of clinical oncology clinical practice guideline update on the use of pharmacologic interventions including tamoxifen, raloxifene, and aromatase inhibition for breast cancer risk reduction. J Clin Oncol. 2009;27:3235-3258.

37. Vogel VG. Raloxifene: a second-generation selective estrogen receptor modulator for reducing the risk of invasive breast cancer in postmenopausal women. Women's Health. 2007;3:139-153.

\section{Publish your work in this journal}

Breast Cancer: Targets and Therapy is an international, peerreviewed open access journal focusing on breast cancer research, identification of therapeutic targets and the optimal use of preventative and integrated treatment interventions to achieve improved outcomes, enhanced survival and quality of life for the cancer patient.

\section{Dovepress}

View the full aims and scopes of this journal here. The manuscript management system is completely online and includes a very quick and fair peer-review system, which is all easy to use. Visit http:// www.dovepress.com/testimonials.php to read real quotes from published authors.

Submit your manuscript here: http://www.dovepress.com/breast-cancer---targets-and-therapy-journal 